\title{
Multilevel, ultra-large-volume epidural blood patch for the treatment of neurocognitive decline associated with spontaneous intracranial hypotension: case report
}

\author{
Michael D. Staudt, MD, MSc, ${ }^{1}$ Stephen H. Pasternak, MD, PhD, ${ }^{1,2}$ Manas Sharma, MD, ${ }^{3}$ \\ Sachin K. Pandey, MD, ${ }^{3}$ Miguel F. Arango, MD, ${ }^{4}$ David M. Pelz, MD, ${ }^{3}$ and Stephen P. Lownie, MD ${ }^{1,3}$ \\ Departments of ${ }^{1} \mathrm{Clinical}$ Neurological Sciences, ${ }^{3}$ Medical Imaging, and ${ }^{4}$ Anesthesia and Perioperative Medicine, London Health \\ Sciences Centre, and ${ }^{2}$ Robarts Research Institute, Western University, London, Ontario, Canada \\ Spontaneous intracranial hypotension $(\mathrm{SIH})$ is a progressive clinical syndrome characterized by orthostatic headaches, \\ nausea, emesis, and occasionally focal neurological deficits. Rarely, $\mathrm{SIH}$ is associated with neurocognitive changes. An \\ epidural blood patch (EBP) is commonly used to treat SIH when conservative measures are inadequate, although some \\ patients require multiple EBP procedures or do not respond at all. Recently, the use of a large-volume (LV) EBP has \\ been described to treat occult leak sites in treatment-refractory SIH. This article describes the management of a patient \\ with profound neurocognitive decline associated with $\mathrm{SIH}$, who was refractory to conservative management and multiple \\ interventions. The authors describe the successful use of an ultra-LV-EBP of $120 \mathrm{ml}$ across multiple levels, the largest \\ volume reported in the literature, and describe the technical aspects of the procedure. This procedure has resulted in \\ dramatic and sustained symptom resolution.
}

https://thejns.org/doi/abs/10.3171/2017.5.JNS17249

KEY WORDS spontaneous intracranial hypotension; cerebrospinal fluid hypovolemia; epidural blood patch; neurocognitive decline; surgical technique

$\mathrm{S}$ PONTANEOUS intracranial hypotension (SIH), also known as CSF hypovolemia, is a progressive and potentially debilitating syndrome characterized by low CSF pressure.? SIH typically results from a CSF leak, most commonly at the level of the spinal cord. ${ }^{15}$ The typical clinical presentation of SIH includes orthostatic headaches, nausea, and/or emesis, with less common symptoms including cranial nerve palsy, gait abnormality, personality change, and memory decline. ${ }^{16}$ In rare cases, coma may occur. $^{4}$

The evaluation of SIH includes brain MRI, which demonstrates characteristic findings that indicate compensation from other intracranial compartments. These findings include diffuse pachymeningeal enhancement and thickening, subdural collections, engorged venous sinuses, flattening of the optic chiasm, pituitary enlargement, and decreased ventricular size. ${ }^{16}$ Spinal MRI, radionuclide cisternography, or myelography is then commonly used to detect a spinal CSF leak. Despite advances in imaging techniques, a focal leak is often not identified, making the diagnosis controversial.

The majority of patients with intracranial hypotension respond to conservative treatment, including bed rest and hydration, although many will require intervention with an epidural blood patch (EBP). ${ }^{1}$ However, some patients may be refractory to conventional therapy, including multiple small-volume (SV) single-site EBP (SV-EBP) injections. Recently, a novel technique has been developed that involves single-catheter access for the administration of a large-volume (LV) EBP (LV-EBP) across multiple levels to target suspected or occult leak sites. ${ }^{6,11}$ The mean volume of these procedures reported in the literature is approximately $50 \mathrm{ml}$, with the largest single volume injected being $75 \mathrm{ml} .{ }^{11}$ We describe the successful use of an ultra-

ABBREVIATIONS EBP $=$ epidural blood patch; $\mathrm{LV}=$ large volume; $\mathrm{MMSE}=$ Mini-Mental State Examination; MoCA $=$ Montreal Cognitive Assessment; SIH $=$ spontaneous intracranial hypotension; SV = small volume.

SUBMITTED January 29, 2017. ACCEPTED May 8, 2017.

INCLUDE WHEN CITING Published online October 6, 2017; DOI: 10.3171/2017.5.JNS17249. 
LV-EBP of $120 \mathrm{ml}$ across multiple levels in the treatment of a patient with SIH and severe neurocognitive symptoms refractory to standard treatment.

\section{Case Report}

History and Examination

A 55-year-old man developed neck pain following a golfing trip, which was further aggravated while lifting heavy furniture. He initially developed a decreased level of consciousness over several hours. Over a period of several days his level of consciousness improved, but he demonstrated profound fatigue and somnolence, and described a dull, orthostatic headache. Most significantly, he developed cognitive impairment and complete loss of shortterm memory. He was initially assessed and subsequently followed in the Cognitive Neurology Clinic of Parkwood Hospital, where he was regularly evaluated using the MiniMental State Examination (MMSE) and Montreal Cognitive Assessment (MoCA; Table 1, Fig. 1A and C). An MR image of his head demonstrated classic findings consistent with intracranial hypotension (Fig. 2A and B), and sequential SV-EBP procedures were arranged. The patient's spouse believed that he was better after each procedure, but the benefit was lost over 2 weeks.

A subsequent MR image of the complete spine revealed multiple large perineural cysts throughout the entire length of the spine, although no evidence of an extraspinal CSF collection was identified. Additional investigations including CT and MR myelography also did not identify a focal leak (Fig. 3). Despite additional EBP procedures, his cognition continued to decline. His MMSE score fell to 20, and his MoCA score fell to 14. He was unable to even complete Part B of the Trail Making test (or TRAILS B; Table 1, Fig. 1A). He then underwent a thoracic laminectomy for marsupialization of the largest cyst at the T10-11 level. Postoperative MRI of the spine confirmed occlusion without evidence of new leakage; however, the patient continued to exhibit somnolence and poor cognitive function. Fibrin glue injections were then performed under CT guidance to target suspected leak sites at the right T6-7, right T11-12, and left T7-8 diverticula. Again, the patient's spouse stated that he was much better after this procedure, but the benefit was lost over 2 weeks.

\section{Operation and Postoperative Course}

Due to the failure of conventional treatments, an LVEBP across multiple levels was proposed to treat a suspected occult CSF leak. At the initial procedure, performed approximately 1.5 years following his initial symptom presentation, $85 \mathrm{ml}$ of autologous blood was infused from levels C-7 through S-3. This resulted in significant improvement in both headache and cognitive function, lasting approximately 3 weeks before further gradual decline. With increasing familiarity with LVEBP, the procedure was then repeated in monthly intervals for the next 3 months, with volumes ranging from 60 to $120 \mathrm{ml}$ and targeting the C-3 through S-3 levels.

Subsequent to the final LV-EBP, the patient finally sustained complete headache resolution, with dramatic and sustained cognitive improvement. Cognitive testing
TABLE 1. Timeline of cognitive testing and treatments

\begin{tabular}{|c|c|c|c|c|}
\hline Timeline & $\begin{array}{c}\text { MMSE } \\
\text { Score }\end{array}$ & $\begin{array}{l}\text { MoCA } \\
\text { Score }\end{array}$ & $\begin{array}{c}\text { TRAILS B } \\
\quad(\mathrm{sec})\end{array}$ & Intervention \\
\hline \multicolumn{5}{|l|}{2013} \\
\hline \multicolumn{5}{|l|}{ March } \\
\hline September & $25 / 30$ & $18 / 30$ & & \\
\hline October & & & & SV-EBP \\
\hline December & $22 / 30$ & $22 / 30$ & & \\
\hline \multicolumn{5}{|l|}{2014} \\
\hline February & & & & SV-EBP \\
\hline March & & & & SV-EBP \\
\hline April & $20 / 30$ & $14 / 30$ & $\begin{array}{l}\text { Unable to } \\
\text { perform }\end{array}$ & \\
\hline July & & & & Operative occlusion \\
\hline August & & $23 / 30$ & & \\
\hline September & & & & Fibrin glue \\
\hline October & $23 / 30$ & $21 / 30$ & & \\
\hline November & & & & LV-EBP (85 ml) \\
\hline \multicolumn{5}{|l|}{2015} \\
\hline January & & $21 / 30$ & & LV-EBP (60 ml) \\
\hline February & & $24 / 30$ & & LV-EBP (115 ml) \\
\hline March & & & & LV-EBP (120 ml) \\
\hline August & $26 / 30$ & $26 / 30$ & 125 & \\
\hline \multicolumn{5}{|l|}{2016} \\
\hline February & $29 / 30$ & $29 / 30$ & 76 & \\
\hline November & & $29 / 30$ & & \\
\hline
\end{tabular}

demonstrated that his MMSE score rose from its lowest score of 20 to 26, and his MoCA score rose from 14 to 26. Whereas before he was unable to perform the TRAILS $\mathrm{B}$ at all, he was now able to perform it in 125 seconds. Over the ensuing 6 months, his MMSE and MoCA scores improved to 29, and his performance on the TRAILS B improved to 76 seconds (Fig. 1B). His most recent MoCA score was 29, 20 months following his last LV-EBP. MRI demonstrated near-complete resolution of the imaging findings related to intracranial hypotension (Fig. $2 \mathrm{C}$ and D). He returned to employment and reacquired his driving license.

\section{Surgical Technique}

The patient was placed prone on the angiography table. Using biplane fluoroscopy (Siemens Neurostar, Siemens Healthcare), an epidural puncture was performed by the anesthetist at either the L2-3 or L3-4 level using a 19-gauge needle, followed by injection of 2-3 ml of contrast (Isovue 200) to confirm epidural positioning of the needle. The neurointerventionalist then passed a Glidewire M 0.035-inch $\times 150$-cm angled-tip Radiofocus guidewire (Terumo Cardiovascular Systems) through the puncture needle and carefully advanced the wire superiorly. The needle was then withdrawn and a 4-Fr Bern Impress 0.035 -inch $\times 100$-cm angiography catheter (Merit Medical Systems, Inc.) was advanced over the guidewire. The catheter and guidewire combination were navigated superiorly 


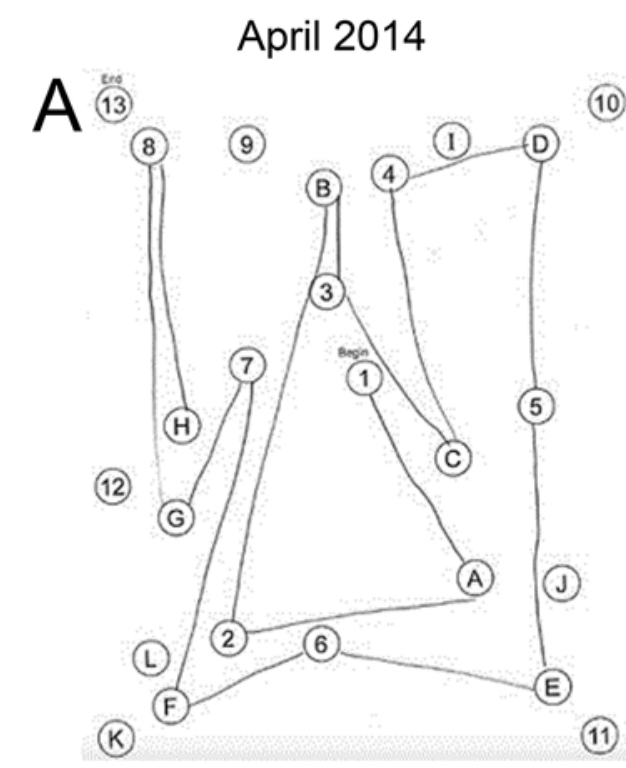

$6 \mathrm{~min} 31 \mathrm{sec}$ (Incomplete)

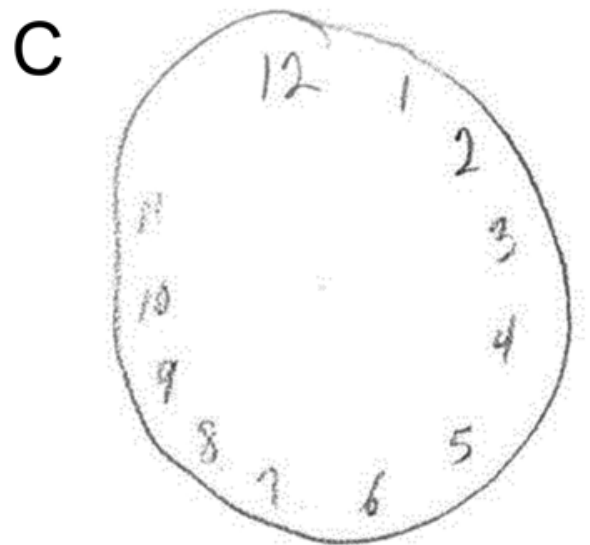

February 2016
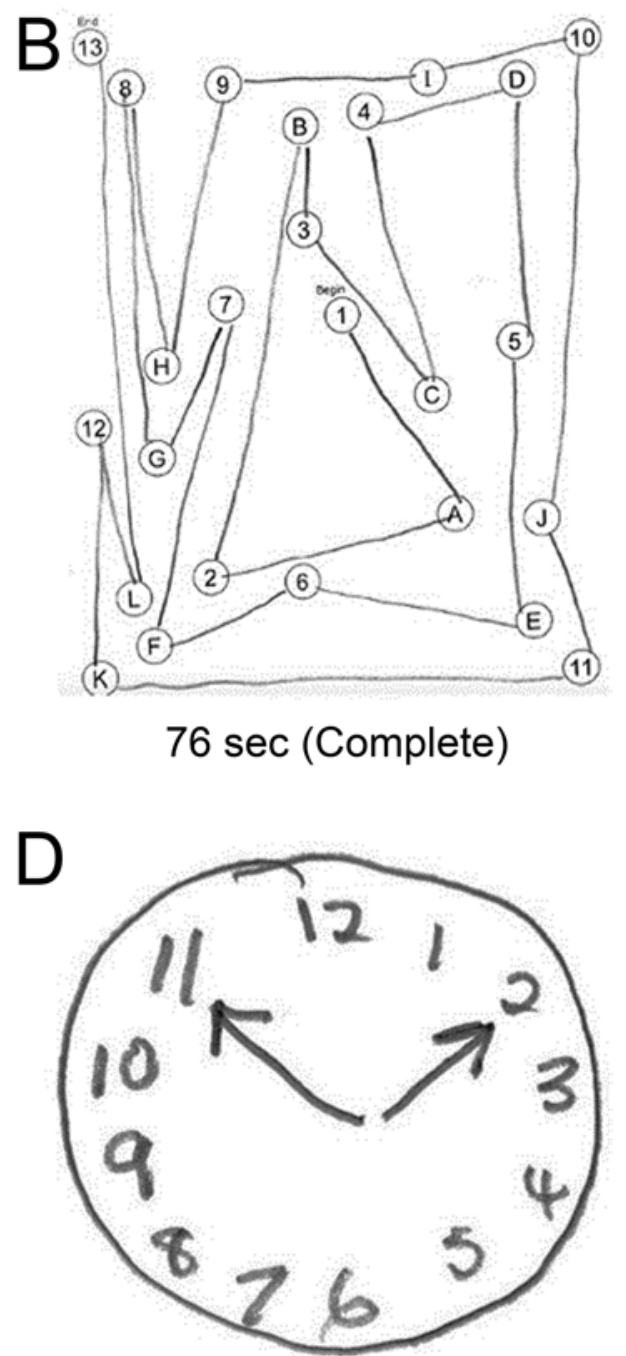

FIG. 1. Results of the MoCA, comparing clinical presentation in April 2014 (A and C, prior to LV-EBP) and February 2016 (B and $D, 11$ months following final LV-EBP). Prior to treatment, the patient was unable to complete the TRAILS B test after 6 minutes 31 seconds (A) or the clock-drawing task (C). Following treatment, the patient had no difficulty performing either task (B, 76 seconds; $\mathbf{D})$.

through the epidural space under biplane fluoroscopy until the tip of the catheter was positioned at the desired cervical level (Fig. 4A-C). The guidewire was then withdrawn.

Autologous blood drawn from a radial arterial line was then carefully injected through the epidural catheter as it was slowly withdrawn from the cervical levels, approximately 2.5-5 $\mathrm{ml}$ at each vertebral level (Fig. 4D and E). After reaching the interspace of initial entry, the catheter was redirected inferiorly to the S1-3 level by reinserting the guidewire and tracking it downward (Fig. 4F); the wire was removed once satisfactory position was achieved and then additional blood was injected, $2.5-5 \mathrm{ml}$ at each level. The catheter was then completely withdrawn. The patient was then transferred to the postanesthesia recovery unit, where he was observed for 2-4 hours. Four procedures were performed in total, with a volume of blood ranging from 60 to $120 \mathrm{ml}$ (mean $95 \mathrm{ml}$ ). There were no immediate or delayed complications related to any of the 4 procedures. Two additional patients have undergone this procedure without complication, using similar volumes of blood (Table 2).

\section{Discussion}

Typical cases of SIH often improve with conservative management, including bed rest, hydration, and caffeine. ${ }^{16}$ When conservative management fails, an EBP or fibrin glue injection may be considered. The mechanism of EBP is believed to be 2-fold: the immediate effect of the injection is to raise the pressure in the epidural and subarachnoid spaces to restore CSF buoyancy and cushioning on the brain, ${ }^{3}$ whereas the long-lasting benefit is derived from sealing of an identified or suspected leak with clot. ${ }^{10}$ As such, the rationale of site-directed EBP or fibrin glue injections presumes focal clot sealing, whereas indirect injections rely on diffusion of blood to a suspected leak site prior to clotting. It has been hypothesized that the formation of an organized clot occurs in stages, such that 

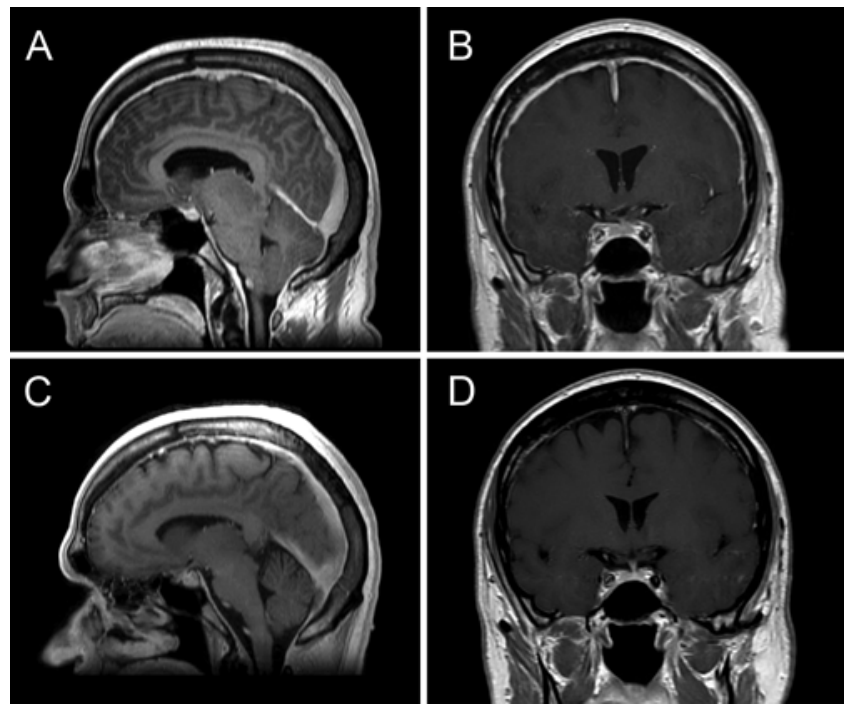

FIG. 2. Sagittal (A and C) and coronal (B and D) T1-weighted Gdenhanced MRI at the level of the sella-pituitary. Baseline imaging demonstrates descent of the cerebellar tonsils below the foramen magnum, deformity of the brainstem, a crowded posterior fossa, and obliteration of the prepontine cistern related to the sinking of the brain $(\mathbf{A})$, as well as diffuse pachymeningeal enhancement (B). Imaging 20 months after final LV-EBP demonstrates the position of the cerebellar tonsils at the foramen magnum, resolution of brainstem sagging, and smaller pituitary (C), as well as resolution of pachymeningeal enhancement (D).

fibroblastic activity occurs within 48 hours followed by collagen deposition at 2 weeks and finally scar formation at 3 months. ${ }^{18}$ An LV-EBP thus avoids the pitfalls associated with SV-EBP in occult CSF leaks, specifically the indirect effect of lumbar access and the technical challenges of site-specific targeting in cervical or thoracic regions. In addition, it provides the greatest surface area to facilitate clot formation.

The LV-EBP technique was first described by Ohtonari et al., who reported their results in 5 patients with SIH and no clearly identified leakage site. ${ }^{11}$ Using a volume of autologous blood ranging from 7 to $75 \mathrm{ml}$, they reported improvement in orthostatic headaches and prevention of chronic subdural hematoma recurrence. No patients presented with neurocognitive decline. This was followed by a larger case series of 9 patients reported by Griauzde et al., all of whom failed site-directed EBP or demonstrated multiple possible leak sites. ${ }^{6}$ These investigators injected between 38 and $70 \mathrm{ml}$ of autologous blood, and reported improvement or resolution in the majority of their patients. Two patients presented with neurocognitive decline, both of whom underwent 2 LV-EBPs. Although "improvement but not to resolution" was reported, our interpretation of these data are limited by the short-term follow-up (2-4 months) and no objective measures of cognitive function.

Neurocognitive dysfunction is among the more rare manifestations of SIH, and can include cognitive decline and memory loss, ${ }^{2,6,12}$ or a constellation of symptoms mimicking frontotemporal dementia ${ }^{8,14,17,19}$ or bipolar disorder. ${ }^{5}$ As such, it is important to distinguish progressive behavioral and cognitive changes in those patients with imaging findings characteristic of SIH. The mechanism by which
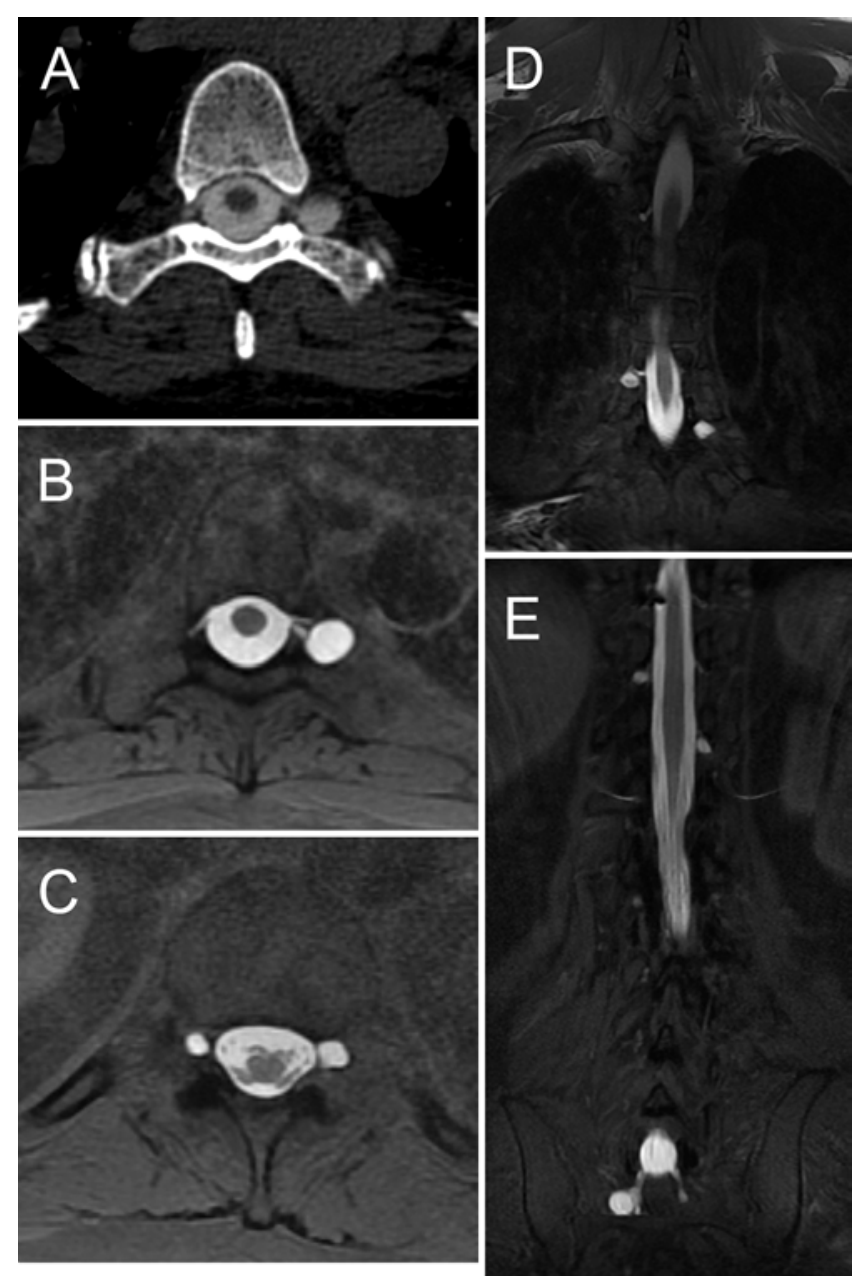

FIG. 3. Left T7-8 diverticula evident on axial CT myelography (A) and axial MR myelography (B). Bilateral T12-L1 diverticula on axial MR myelography (C). Multiple diverticula on coronal MR myelography, including sacral diverticula (D and E). There was no evident CSF leak in any of the images.

SIH causes cognitive and behavioral disturbances is not known. It has been hypothesized that the lack of CSF cushioning may lead to compression of the frontal and temporal cortices ${ }^{8}$ or that blood stasis via venous engorgement causes frontotemporal circuitry dysfunction. ${ }^{14}$ Certainly, there is distortion of both cortical and diencephalic structures from a mechanical and vascular standpoint, which undoubtedly disrupts circuitry to some degree. An individual's response may be explained by the degree of deformation, his or her cognitive reserve, or a combination of other factors.

Because LV-EBP is a novel procedure with limited literature, the risk profile is not known. Neither Ohtonari et al. nor Griauzde et al. reported any adverse outcomes other than mild postprocedural headaches. ${ }^{6,11}$ Theoretically, LV-EBP could lead to epidural abscesses or symptomatic epidural hematomas, although the incidence of these is rare in the conventional literature. ${ }^{9,13}$ There is also the potential for injury to a neural structure during the introduction of the catheter, and the difficulty in navigating around the epidural scar from previous procedures. Al- 


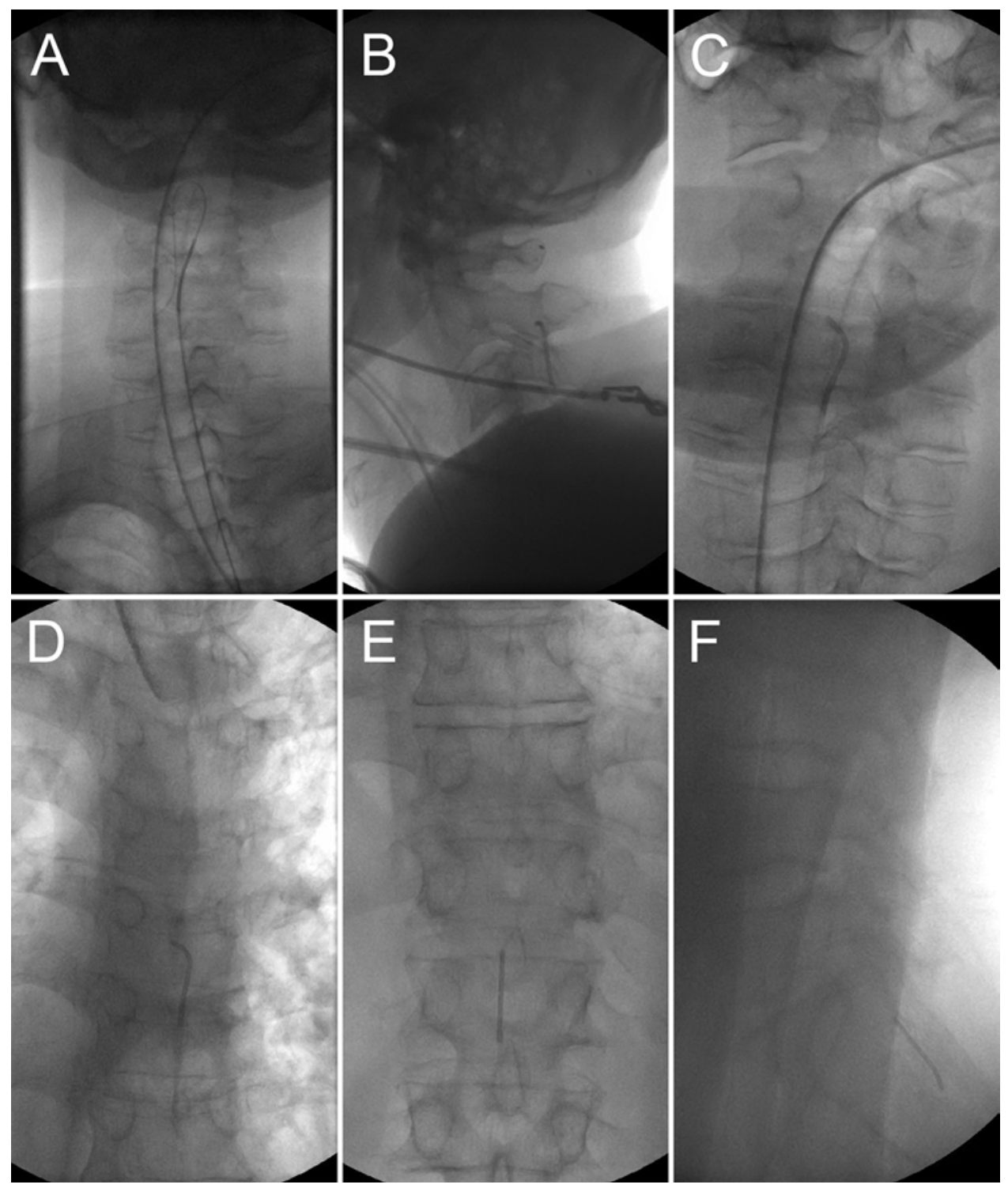

FIG. 4. Epidural catheter placement across multiple spinal levels under fluoroscopic guidance. The catheter and guidewire are first advanced to the upper cervical levels (A). After removal of the guidewire, autologous blood is injected as the catheter is slowly withdrawn across the cervical (B and C), thoracic (D), and lumbar (E) levels. Once the interspace of initial entry has been reached, the catheter is redirected inferiorly to the sacral levels for additional injections $(\mathbf{F})$.

TABLE 2. Characteristics of 2 additional patients with SIH who underwent multilevel, ultra-LV-EBP

\begin{tabular}{|c|c|c|c|c|}
\hline $\begin{array}{l}\text { Age (yrs), } \\
\quad \text { Sex }\end{array}$ & Clinical Symptoms & $\begin{array}{c}\text { 1st/2nd/3rd } \\
\text { LV-EBPs (ml) }\end{array}$ & $\begin{array}{c}\text { Cognitive Testing } \\
\text { (baseline to most recent) }\end{array}$ & Outcome \\
\hline $56, \mathrm{M}$ & $\begin{array}{l}\text { Neurocognitive decline, } \\
\text { diplopia, headache, } \\
\text { impaired balance, It } \\
\text { hemifacial spasm }\end{array}$ & $75 / 115 / 60$ & $\begin{array}{l}\text { MoCA: } 23 / 30 \\
\text { MMSE: } 27 / 30 \\
\text { MoCA: } 23 / 30 \\
\text { TRAILS B: } 213 \mathrm{sec}\end{array}$ & $\begin{array}{l}\text { Headache \& diplopia resolved; improved hemifacial spasm; } \\
\text { improved tonsillar herniation, more CSF w/in prepontine } \\
\text { cistern on MRI; neurocognitive symptoms stable; early } \\
\text { results, will continue to follow }\end{array}$ \\
\hline $61, \mathrm{M}$ & $\begin{array}{l}\text { Neurocognitive decline, } \\
\text { headache, dysarthria, } \\
\text { dysphagia, impaired } \\
\text { balance }\end{array}$ & $85 / 120 / 110$ & $\begin{array}{l}\text { MoCA: } 19-21 / 30 \\
\text { MoCA: } 23-26 / 30\end{array}$ & $\begin{array}{l}\text { Atypical SIH presentation; chronic transtentorial herniation } \\
\text { w/o other characteristic SIH features on MRI, not improved } \\
\text { on follow-up; persistent somnolence \& depressed mood }\end{array}$ \\
\hline
\end{tabular}


though the volume of injected blood can be quite high, it is often less than $5 \mathrm{ml}$ per vertebral level. We describe a multilevel injection of $120 \mathrm{ml}$ without immediate or delayed complications, and 20-month follow-up demonstrating sustained cognitive improvement. Furthermore, we have now successfully applied this technique to 3 patients with SIH using similar volumes without complication (Table 2). However, these results should be interpreted with caution due to the small number of patients treated.

Our experience suggests that a multilevel, LV-EBP is a promising treatment for refractory SIH compared with multiple SV procedures, and may safely be performed up to volumes of $120 \mathrm{ml}$ in a single setting. The ability to target multiple levels with a large surface area of autologous blood is more likely to cover a suspected leak site. Thus, the true effectiveness of this procedure may be for patients with multilevel or occult CSF leaks. Multiple procedures may be necessary to facilitate clot and scar formation before symptoms and signs finally improve, as illustrated in the present case. Conversely, this procedure is likely not necessary in those cases in which a focal CSF leak is identified. Although the clinical presentation of neurocognitive decline in patients with $\mathrm{SIH}$ is rare, symptoms should warrant a thorough investigation for this potentially treatable etiology. Larger patient populations and long-term followup are warranted to assess the efficacy and safety of this procedure.

\section{References}

1. Amoozegar F, Guglielmin D, Hu W, Chan D, Becker WJ: Spontaneous intracranial hypotension: recommendations for management. Can J Neurol Sci 40:144-157, 2013

2. Beck CE, Rizk NW, Kiger LT, Spencer D, Hill L, Adler JR: Intracranial hypotension presenting with severe encephalopathy. Case report. J Neurosurg 89:470-473, 1998

3. Carrie LE: Epidural blood patch: why the rapid response? Anesth Analg 72:129-130, 1991

4. Evan RW, Mokri B: Spontaneous intracranial hypotension resulting in coma. Headache 42:159-160, 2002

5. Fitzek S, Smesny S, Fitzek C, Axer H, Wohlfarth M, Vieweg $\mathrm{U}$, et al: Organic bipolar disorder occurring together with spontaneous intracranial hypotension. Psychiatry Res 131:177-183, 2004

6. Griauzde J, Gemmete JJ, Chaudhary N, Wilson TJ, Pandey AS: Large-volume blood patch to multiple sites in the epidural space through a single-catheter access site for treatment of spontaneous intracranial hypotension. AJNR Am J Neuroradiol 35:1841-1846, 2014

7. Headache Classification Committee of the International Headache Society (IHS): The International Classification of Headache Disorders, 3rd edition (beta version). Cephalalgia Int J Headache 33:629-808, 2013

8. Hong M, Shah GV, Adams KM, Turner RS, Foster NL: Spontaneous intracranial hypotension causing reversible frontotemporal dementia. Neurology 58:1285-1287, 2002

9. Horlocker TT, Wedel DJ: Neurologic complications of spinal and epidural anesthesia. Reg Anesth Pain Med 25:83-98, 2000

10. Kroin JS, Nagalla SK, Buvanendran A, McCarthy RJ, Tuman KJ, Ivankovich AD: The mechanisms of intracranial pressure modulation by epidural blood and other injectates in a postdural puncture rat model. Anesth Analg 95:423-429, 2002

11. Ohtonari T, Ota S, Nishihara N, Ota T, Tanaka Y, Sekihara Y, et al: A novel technique of multiple-site epidural blood patch administration for the treatment of cerebrospinal fluid hypovolemia. J Neurosurg 116:1049-1053, 2012

12. Peng PW: Intracranial hypotension with severe neurological symptoms resolved by epidural blood patch. Can J Neurol Sci 31:569-571, 2004

13. Pöpping DM, Zahn PK, Van Aken HK, Dasch B, Boche R, Pogatzki-Zahn EM: Effectiveness and safety of postoperative pain management: a survey of 18925 consecutive patients between 1998 and 2006 (2nd revision): a database analysis of prospectively raised data. Br J Anaesth 101:832-840, 2008

14. Sayao AL, Heran MK, Chapman K, Redekop G, Foti D: Intracranial hypotension causing reversible frontotemporal dementia and coma. Can J Neurol Sci 36:252-256, 2009

15. Schievink WI, Maya MM, Jean-Pierre S, Nuño M, Prasad RS, Moser FG: A classification system of spontaneous spinal CSF leaks. Neurology 87:673-679, 2016

16. Urbach H: Intracranial hypotension: clinical presentation, imaging findings, and imaging-guided therapy. Curr Opin Neurol 27:414-424, 2014

17. Walker L, DeMeulemeester C: Spontaneous intracranial hypotension masquerading as frontotemporal dementia. Clin Neuropsychol 22:1035-1053, 2008

18. Weitz SR, Drasner K: Spontaneous intracranial hypotension: a series. Anesthesiology 85:923-925, 1996

19. Wicklund MR, Mokri B, Drubach DA, Boeve BF, Parisi JE, Josephs KA: Frontotemporal brain sagging syndrome: an SIH-like presentation mimicking FTD. Neurology 76:13771382,2011

\section{Disclosures}

The authors report no conflict of interest concerning the materials or methods used in this study or the findings specified in this paper.

\section{Author Contributions}

Conception and design: Staudt, Pasternak, Lownie. Acquisition of data: Staudt, Pasternak, Sharma, Pandey, Arango, Lownie. Analysis and interpretation of data: Staudt, Pasternak, Lownie. Drafting the article: Staudt, Pasternak, Sharma, Lownie. Critically revising the article: Staudt, Pasternak, Lownie. Reviewed submitted version of manuscript: Staudt, Pasternak, Lownie. Approved the final version of the manuscript on behalf of all authors: Staudt. Administrative/technical/material support: Sharma, Pandey, Arango, Pelz, Lownie. Study supervision: Pasternak, Pelz, Lownie.

\section{Correspondence}

Michael D. Staudt, Department of Clinical Neurological Sciences, London Health Sciences Centre, Western University, 339 Windermere Rd., London, Ontario N6A 5A5, Canada. email: michael. staudt@londonhospitals.ca. 